\title{
Effect of the different assays of HbA1c on diabetic patients monitoring
}

\author{
Farideh Razi ${ }^{1}$, Ensieh Nasli Esfahani ${ }^{1}$, Marjan Rahnamaye Farzami ${ }^{2}$, Ali Tootee ${ }^{1}$, Mostafa Qorbani ${ }^{3,4}$, \\ Soltan Ahmad Ebrahimi ${ }^{5}$, Mehrzad Nahid ${ }^{5}$ and Parvin Pasalar ${ }^{6 *}$
}

\begin{abstract}
Background: HbA1c test is widely used for glycemic monitoring of diabetic patients. This study aimed to evaluate clinical performance of different assays for classification of patients into controlled and uncontrolled group base on ADA recommendations.

Method: A total of 154 samples from patients with diabetes type 2 with HbA1c concentration covering the whole clinical range were analyzed by four commercially methods; D-10 Hb A1c (Bio-Rad Laboratories), Cobas Integra 400 (Roche Diagnostics), NycoCard Reader II (Axis-Shield) and DS5 (Drew Scientific). For each individual assay, patient's results were classified into controlled and uncontrolled groups (less or more than three decision levels; $6.5 \%, 7 \%$ and $8 \%)$ compared to D10 results as reference method. The frequency of each group and also sensitivity, specificity, negative and positive predictive value were estimated.

Results: We found a significant correlation between assays (r: 0.937-0.945). Sensitivity, specificity, and positive and negative predictive values of the evaluated method to identify uncontrolled patients were as follows: 49.2-95.7\%, 86.5-100 \%, 89.1-100\%, and 52.9-93.3\%; respectively.

Conclusions: Results show that some HbA1c assays capability to classify diabetic patients according to HbA1c level is still unacceptable.
\end{abstract}

Keywords: HbA1c, Glycemic control, Decision level, Diabetes

\section{Introduction}

Measurement of HbA1c concentration can be considered as a useful indicator of glycemic control in diabetic patients. Moreover, it is documented that high HbA1c levels are correlated with development of different diabetes complications. Measurement of HbAlc has more advantages over both assessment of the fasting plasma glucose and glucose tolerance test. It is more convenient, does not require fasting, has increased preanalytical stability, is less likely to differ in different days due to stress or illness $[1,2]$.

HbA1c testing is also useful in diseases other than diabetes. Van't Riet in a 10 year follow-up study (Hoorn Study) found that, in non-diabetic persons between 50

\footnotetext{
* Correspondence: pasalar@tums.ac.ir

${ }^{6}$ Endocrinology and Metabolism Research Center, Endocrinology and

Metabolism Clinical Sciences Institute, Tehran University of Medical Sciences, Tehran, Iran

Full list of author information is available at the end of the article
}

and 75 years of age, $\mathrm{HbA} 1 \mathrm{c}$ measurement was a superior predictor of 10 year cardiovascular events (fatal and non-fatal) and all-cause mortality, in comparison with fasting and $2 \mathrm{~h}$ postprandial glucose [3]. Moreover, the findings of the North American Atherosclerosis Risk in Communities (ARIC) study demonstrated that HbA1c was a better predictor of diabetes and cardiovascular disease in comparison with fasting glucose in patients without diagnosed diabetes [4]. Reducing $\mathrm{Hb} \mathrm{Alc}$ concentrations to $7 \%$ or below is demonstrated to be correlated with significant decrease in the rate of different microvascular complications of diabetes. Although it is recommended that $\mathrm{Hb} \mathrm{A} 1 \mathrm{c}$ levels in non-pregnant adults should be kept less than $7 \%$, more stringent A1c (6.5\%) and mild A1c goals (8\%) may also be recommended for some patient considering their specific situation [2].

Results of one single assessment of HbA1c can provide clinicians with the best determinant of glycemic control
C Biomed Central

(C) 2015 Razi et al. Open Access This article is distributed under the terms of the Creative Commons Attribution 4.0 International License (http://creativecommons.org/licenses/by/4.0/), which permits unrestricted use, distribution, and reproduction in any medium, provided you give appropriate credit to the original author(s) and the source, provide a link to the Creative Commons license, and indicate if changes were made. The Creative Commons Public Domain Dedication waiver (http://creativecommons.org/publicdomain/zero/1.0/) applies to the data made available in this article, unless otherwise stated. 
in patients and clinical decision-making can be effectively guided by it [5]. Therefore, it can be concluded that the assays for determination of HbA1c levels need to be accurate, precise and consistent to be able to effectively employed by clinicians.

Currently, there exist an exceeding number of 30 different HbA1c assays on the market and they all perform based on two different principles, one of them being the separation of $\mathrm{Hb}$ fractions, and the other, on chemical reaction. It is noteworthy however that all of the mentioned assays need to be standardized based on National Glycohemoglobin Standardization Program (NGSP) [6-8].

When choosing an HbA1c measurement method, laboratories should first analyze the method in terms of its being NGSP certified (potential for optimal performance) and then assess proficiency testing data (both current and past surveys) to predict the actual performance of it. Although selection of a NGSP certified method which has successfully passed proficiency testing is very important, it does not still does not guarantee optimal performance in all laboratories [9].

Despite considerable achievements of NGSP in terms of validity of different HbA1c techniques, it is documented that the existing variability among NGSPcertified methods can still undermine clinical diagnostic value of HbA1c testing $[10,11]$.

The current study is designed to assess discrepancies between HbA1c results obtained by D10-HPLC as reference method and other evaluated assays to determine the diversity in categorization of individual patients in regard to their glycemic control (HbA1c less or more than three decision level; $6.5 \%, 7 \%$ and $8 \%$ ). We assessed the variability of the results obtained from different techniques in two groups: those with controlled blood glucose levels, and the patients with uncontrolled glucose concentrations.

\section{Materials and methods}

A total of 154 samples from diabetic patients with HbA1c concentration covering the whole clinical range, were obtained through venipuncture into sterile tubes containing the EDTA $K_{2}$ and tested with 4 assays within 2 days. No more inclusion criteria were used.

It needs to be mentioned that the study was approved by the Ethics Committee of Endocrinology metabolism Research Institute and all participants gave written informed consent.

HbA1c measurement was performed concurrently in all cases by four commercially available assays:

1. D-10 Hb A1c (Bio-Rad Laboratories, Hercules, CA), Ion exchange HPLC method

2. Cobas Integra 400 (Roche Diagnostics, Mannheim, Germany), Immunoassay
3. NycoCard Reader II, (Axis-Shield, Oslo, Norway), Boronate affinity chromatography

4. DS5, (Drew Scientific, Le Rheu, France), Ion exchange chromatography

Of these, three methods are currently certified by the National Glycohemoglobin Standardization Program (D-10 Hb A1c, Cobas Integra 400 and NycoCard Reader II).

According to recommendations from the American Diabetes Association (ADA), three decision level for diabetic patients monitoring ( $6.5 \%, 7 \%$ and $8 \%$ ) were considered and patients were classified based on their glycemic status by each method (HbA1c $<$ cut off and HbA1c $\geq$ cut off). After calculation of frequency of each group for each method, sensitivity, specificity, and positive and negative predictive values of the different method were estimated. D10 was considered as the reference method. Total precision of each assay was also evaluated using CLSI EP15-A2 protocol [12].

Data were processed with the statistical software, SPSS version 15. Mean and Standard Deviation, $\mathrm{p}$ value and correlation coefficient were calculated. Sensitivity, specificity, and positive predictive values (PPV) and negative predictive values (NPV) of the three assays were estimated.

\section{Results}

Total precision (in term of CV\%) were less than $1.6 \%$, $1.0 \%, 3.1 \%$ and $3.3 \%$ for D10, cobas integra 400 , Nycocard reader II and DS5 respectively. The mean $\pm \mathrm{SD}$ value of HbA1c was significantly higher when measured by D10 $(7.59 \% \pm 1.43 \%)$ than when estimated with the Nycocard reader II $(6.87 \% \pm 1.17 \%$, r: 0.937, $\mathrm{P}<0.05)$ and DS5 $(6.69 \pm 1.47 \%, \mathrm{r}: 0945, \mathrm{P}<0.05)$ and almost same compared to cobas integra 400 (7.66 \pm 1.45 , r: 0.944, P: 0.06). For each individual assay, patient's results were classified into controlled and uncontrolled groups compared to D10 results and the frequencies of each group were estimated (Tables 1, 2, 3). In three cut points when using Nycocard, $17.1 \%, 26.5 \%$ and $50.8 \%$ of patients could be misclassified as controlled. The same results $(27.4 \%, 33.3 \%$ and $46 \%)$ were found when using DS5. The results were less than $9.5 \%$ for cobas integra. Sensitivity, Specificity, Negative and positive predictive value were shown in Table 4.

\section{Discussion}

The finding of our study demonstrated that although different measurement methods for HbA1c concentrations show very good correlation but might be different in patients with different glycemic control goals. This variation in patients, in turn, might cause confusion in clinicians and affect the proper decision-making. 
Table 1 Classification of patients at HbA1c level $6.5 \%$

\begin{tabular}{clll}
\hline & \multicolumn{2}{l}{ D10 } & \\
\cline { 2 - 4 } Cobas Integra 400 & $<6.5$ & $\geq 6.5$ & Total \\
\hline$<6.5$ & 34 & 5 & 39 \\
$\geq 6.5$ & 3 & 112 & 115 \\
Total & 37 & 114 & 154 \\
Nycocard reader II & $<6.5$ & $\geq 6.5$ & Total \\
$<6.5$ & 37 & 20 & 58 \\
$\geq 6.5$ & 0 & 97 & 97 \\
Total & 37 & 117 & 154 \\
DS5 & $<6.5$ & $\geq 6.5$ & Total \\
$<6.5$ & 36 & 32 & 68 \\
$\geq 6.5$ & 1 & 85 & 86 \\
Total & 37 & 117 & 154 \\
\hline
\end{tabular}

In our study, Nycocard reader II and DS5 were less sensitive than cobas integra at three cut points: $6.5 \%$, $7 \%$, and $8 \%$. When Nycocard or DS5 were used, $17.1 \%-50.8 \%$ and $27.4-46 \%$ of patients were mistakenly identified as the control group. Cobas integra 400 had best ability to detect patients who their results were more or less than predefined decision level and only $4.3 \%, 6.9 \%$ and $9.5 \%$ could be underestimated. Fortunately positive predictive value for all evaluated assay was more than $89 \%$ which means the results more than decision level are much more reliable.

In similar study designed by García-Alcalá et al., the authors evaluated the performance of an immunoturbidimetric inhibition assay (Dimension, Dade Behring) and compared it with the HPLC method (Biorad D10). Their findings demonstrated sensitivity and specificity of $78 \%$ and $88 \%$, respectively, in screening patients with HbA1c levels more than $7 \%$ [5]. In the present

Table 2 Classification of patients at HbA1c level $7 \%$

\begin{tabular}{|c|c|c|c|}
\hline \multirow[b]{2}{*}{ Cobas Integra 400} & \multicolumn{3}{|c|}{ D10 } \\
\hline & $<7$ & $\geq 7$ & Total \\
\hline$<7$ & 45 & 7 & 52 \\
\hline$\geq 7$ & 7 & 95 & 102 \\
\hline Total & 52 & 102 & 154 \\
\hline Nycocard reader II & $<7$ & $\geq 7$ & Total \\
\hline$<7$ & 52 & 27 & 81 \\
\hline$\geq 7$ & 0 & 75 & 75 \\
\hline Total & 52 & 102 & 154 \\
\hline DS5 & $<7$ & $\geq 7$ & Total \\
\hline$<7$ & 52 & 34 & 86 \\
\hline$\geq 7$ & 0 & 68 & 68 \\
\hline Total & 52 & 102 & 154 \\
\hline
\end{tabular}

Table 3 Classification of patients at HbA1c level $8 \%$

\begin{tabular}{clll}
\hline & \multicolumn{2}{l}{ D10 } & \\
\cline { 2 - 4 } Cobas Integra 400 & $<8$ & 28 & Total \\
\hline$<8$ & 7 & 57 & 90 \\
$\geq 8$ & 91 & 63 & 64 \\
Total & $<8$ & $\geq 8$ & 154 \\
Nycocard reader II & 90 & 32 & Total \\
$<8$ & 1 & 31 & 122 \\
$\geq 8$ & 91 & 63 & 32 \\
Total & $<8$ & $\geq 8$ & 154 \\
DS5 & 90 & 29 & Total \\
$<8$ & 1 & 34 & 119 \\
$\geq 8$ & 91 & 63 & 35 \\
Total & & 154 \\
\hline
\end{tabular}

study, we observed that immunoassay method (cobas integra) demonstrated sensitivity and specificity of $93.1 \%$ and $86.5 \%$ respectively at HbA1c level $7 \%$. In a study designed by Schwartz et al., point-of-care testing devices (POCT) were investigated and the results were compared with that of the central labs with which all of them were aligned to DCCT (Diabetes Control and Complications Trial) and NGSP. Their findings demonstrated that the sensitivity of POCT devices in detecting patients with HbA1c levels higher than $7 \%$ was $81.8 \%$ [13]. In the current study, the sensitivity of Nycocard reader II as a POCT device was estimated about $73.5 \%$. Few studies have been done about $\mathrm{HbA} 1 \mathrm{c}$ assays performance in Iran with the main focus on persistence of bias in different assay. Karami study showed unacceptable bias in four HbA1c assays including Nycocard [14]. The same results have been achieved by Keramati et al. study

Table 4 Sensitivity and Specificity of three assays at different Cut Point Compared to D10 Result

\begin{tabular}{cllll}
\hline & Sensitivity \% & Specificity \% & PPV \% & NPV \% \\
A1C level 6.5 \% & & & & \\
\hline Cobas Integra 400 & 95.7 & 91.9 & 97.4 & 87.2 \\
Nycocard reader II & 82.9 & 100.0 & 100.0 & 64.9 \\
DS5 & 72.6 & 97.3 & 98.8 & 52.9 \\
A1C level 7 \% & & & & \\
Cobas Integra 400 & 93.1 & 86.5 & 93.1 & 86.5 \\
Nycocard reader II & 73.5 & 100.0 & 100.0 & 65.8 \\
DS5 & 66.7 & 100.0 & 100.0 & 60.5 \\
A1C level 8 \% & & & & \\
Cobas Integra 400 & 90.5 & 92.3 & 89.1 & 93.3 \\
Nycocard reader II & 49.2 & 98.9 & 96.9 & 73.8 \\
DS5 & 54.0 & 98.9 & 97.1 & 75.6 \\
\hline
\end{tabular}


which evaluated five HbA1c assays including Nycocard and DS5 [15].

Our results show that being NGSP certified is not enough and the more attention to proficiency testing results and also validation of assays in each laboratory is recommended.

\section{Competing interests}

The authors declare that they have no competing interests.

\section{Authors' contributions}

PP and FR proposed the concept of study. FR and MRF did the analytical aspects of the study. MQ analyzed the results. Initial draft of the manuscript was written by ENE and AT, which was reviewed and edited by PP. All authors read and approved the final manuscript.

\section{Acknowledgment}

This project has been funded by the Diabetes Research Center, Endocrinology and Metabolism Clinical Sciences Institute as a part of an endocrinology subspecialty fellowship thesis.

\section{Author details}

${ }^{1}$ Diabetes Research Center, Endocrinology and Metabolism Clinical Sciences Institute, Tehran University of Medical Sciences, Tehran, Iran. ${ }^{2}$ Reference Health Laboratory of Iran, Ministry of Health, Tehran, Iran. ${ }^{3}$ Department of Community Medicine, Alborz University of Medical Sciences, Karaj, Iran. ${ }^{4}$ Non communicable Diseases Research Center, Endocrinology and Metabolism Population, Sciences Institute, Tehran University of Medical Sciences, Tehran, Iran. ${ }^{5}$ Massoud Clinical Laboratory, Tehran, Iran. ${ }^{6}$ Endocrinology and Metabolism Research Center, Endocrinology and Metabolism Clinical Sciences Institute, Tehran University of Medical Sciences, Tehran, Iran.

Received: 9 February 2015 Accepted: 22 July 2015

Published online: 04 August 2015

\section{References}

1. Nathan DM, Buse JB, Davidson MB, Heine RJ, Holman RR, Sherwin R, et al. Management of hyperglycemia in type 2 diabetes: A consensus algorithm for the initiation and adjustment of therapy a consensus statement from the American Diabetes Association and the European Association for the study of diabetes. Diabetes Care. 2006;29(8):1963-72.

2. American Diabetes Association. Standards of medical care in diabetes 2014. Diabetes Care. 2014;37(1):S14-80.

3. Van't Riet E, Rijkelijkhuizen JM, Alssema M, Nijpels G, Stenouwer CDA, Heine $\mathrm{RJ}$, et al. HbA1c is an independent predictor of non-fatal cardiovascular disease in a Caucasian population without diabetes: a 10-year follow-up of the Hoorn Study. Eur J Prev Cardiol. 2012;19(1):23-31.

4. Selvin E, Steffes MW, Zhu H, Matsushita K, Wagenknecht L, Pankow J, et al. Glycated hemoglobin, diabetes, and cardiovascular risk in nondiabetic adults. N Engl J Med. 2010;362(9):800-11.

5. García-Alcalá H, Ruiz-Argüelles A, Cedillo-Carvallo B. Effect of the method to measure levels of glycated hemoglobin on individual clinical decisions comparison of an immunoassay with high-performance liquid chromatography. Am J Clin Pathol. 2009;132(3):332-5.

6. Weykamp C, John WG, Mosca A. A Review of the Challenge in Measuring Hemoglobin A1c. J Diabetes Sci Technol. 2009;3(3):439-45.

7. Lenters-Westra E, Schindhelm RK, Bilo HJ, Slingerland RJ. Haemoglobin A1C. Historical overview and current concepts. Diabetes Res Clin Pract. 2013;99(2):75-84.

8. Higgins T. HbA1c An analyte of increasing importance. Clin Biochem. 2012;45(13):1038-45.

9. Little RR. Performance of hemoglobin a1c assay methods: good enough? Clin Chem. 2014;60(8):1031-3.

10. Genc S, Gurdol F, Kanmaz-Ozer M, Ince N, Ozcelik F. The Analytical Performances of Four Different Glycated Hemoglobin Methods. Med Chem. 2014:4:501-5.

11. Holmes EW, Erşahin Ç, Augustine GJ, Charnogursky GA, Gryzbac M, Murrell JV, et al. Analytic Bias Among Certified Methods for the Measurement of Hemoglobin A1c A Cause for Concern? Am J Clin Pathol. 2008;129(4):540-7.
12. Carey RN. User Verification of Performance for Precision and Trueness: Approved Guideline: Clinical and Laboratory Standards Institute. 2006.

13. Schwartz KL, Monsur J, Hammad A, Bartoces MG, Neale AV. Comparison of point of care and laboratory HbA1c analysis: a MetroNet study. J Am Board Family Med. 2009;22(4):461-3.

14. Karami A, Baradaran A. Comparative evaluation of three different methods for HbA1c measurement with High-performance liquid chromatography in diabetic patients. Advanced Biomed Res. 2014;3.

15. Keramati T, Tootee A, Esfahani EN, Qorbani M, Pasalar P, Razi F. Evaluation of the Analytical Performance of Five Assays in Measurement of Hemoglobin A1c in Iran. Thrita. 2015;4(2):e26549.

\section{Submit your next manuscript to BioMed Central and take full advantage of:}

- Convenient online submission

- Thorough peer review

- No space constraints or color figure charges

- Immediate publication on acceptance

- Inclusion in PubMed, CAS, Scopus and Google Scholar

- Research which is freely available for redistribution 